Artigos 


\title{
O RELACIONAMENTO AMOROSO ENTRE $O$ CAVALEIRO E A FADA NOS "LAIS" MEDIEVAIS
}

Antonio P. Y. Morcis*

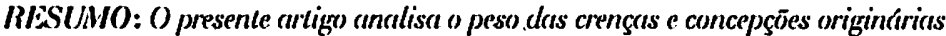
cka cullurre folclórica, estabelecick nos termos de uma oralidade, na definiçäo da

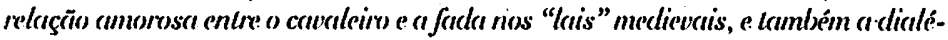
lica dess interraģöes entre estas crenças e concepç̄öes a a élica do amor corlês ja insimusada na produçäo literiria em lingua vulgar de meados do século XII.
\end{abstract}

PAIAVIRAS-CIIAVI: Crençrıs; concepşöes; cullura folclórica; oralidade; dialélica das interraçöes; élica do amor cortês; produçāo literúrió.

Dentre os gêneros literários que despontam no século XII, com a formação de um ambiente cortesão, o "lai" aprescnta caractcrísticas que lhe são cxclusivas. Pode-sc defini-lo como um pocma narrativo curto, que prima pela contenção c reduz o discurso ao estrito mínimo'. Na origem o "lai" cra um pocma cantado com acompanhamento instrumental, c suas raízes são indubitavclmente bretãs, fato confirmado pclos próprios autores que lhe deram uma versão cscrita. Maric de France, a única autora deste gênero de obras de que a história houve por bem nos legar o nome, afirma textualmente na introdução do "Lai de Cuigemar":

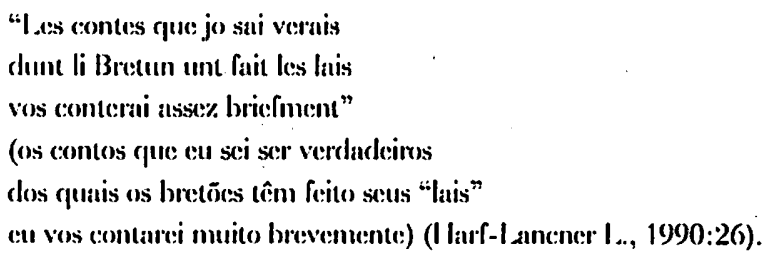

(") Universidade de São Paulo - USP. Agradecimentos ao meu orientador, prof. Jônatas Batista Neto e à prof”. Lênia Márcia Mongelli.

(1) Sobre a definiçāo dos "lais" narrativos ver Jodogne O. et Payen J. C., 1975:38-40. 


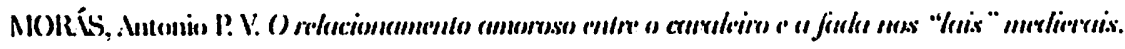

$\therefore$

Limbora cm princípio fossem obras cantarlas, parece que os "lais" de Maric de lirance foram compostos de forma a prescindir de qualcpuer aparato musical. Como a própria autora o diz no prólogo de sua obra:

HRinte on ai s: faic ditis

soventes reiz o: ai veillis:"

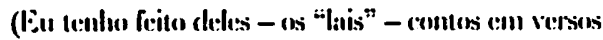

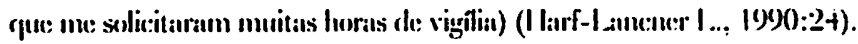

li provívet, contudo, que alguns "lais" anônimos fossem cantados com acompanhamento de instrumentos. 0 anônimo autor do "lai de Graclent" abre seu cscrito dizendo:

"bon cen some li lai in cir

Q: lis motos a retonir"

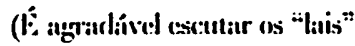

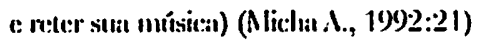

Entretanto, ainda que um manuscrito medieval contendo "lais" anônimos cheğasse a apresentar traços de notaçöes musicais, dificilmente estas obras terian conservado a melodia original em que costumavam ser cantadas na Bretanha liancesa ou em Cales, terras que se notabilizaram como autênticos repositórios das tradiçōes célticas".

Os "lais" de Maric de Prance, por sua qualidarle literiulia e seu refinannento estético, são quase uma síntese do gênero, mas existem ainda outros "lais", compostos posteriormente aos de Narie por um ou mais alutores anônimos, que, cmbora menos sofisticados de: $\mathbf{u m}$ ponto de vista literário, permanecem mais próximos das crengas e lendas folclóricas de: liundo céltico. Algums destes "lais" anônimos têm por tema precisamente o relacionamento amoroso entre um mortal e um ser férico, o qual também porle ser encontrado em certos "lais" de Maric de lirance.

(2) Sobre o manuscrito contendo os "lais" anônimos ver Paris G., 1879:29-72. 


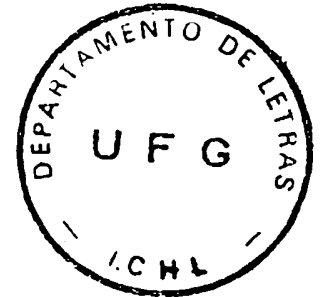

O objetivo deste estudo scrá analisar a mancira como são representados o cavalciro e a fada cnquanto protagonistas de uma rclação amorosa que se desenvolve no decorrer do "lai", levando em conta as crenças c concepgễes concernentes às fadas, oriundas da cultura folclórica, c também as inflexōes ou transformações observadas neste corpo de referenciais folclóricos por ocasião da confeç̧ão de um relato direcionado a um público cortesão. Para o propósito deste estudo será dada primazia ao "Lai de Lanval", de Maric de lìrance, c também aos anônimos "Lai de Craclent" c "I Jai de Desiré", uma vez que o enredo destas obras organizat-se em torno da relação que se cstabelece entre o cavalciro c a fada. O "lai" anônimo de Cuingamor; cmbora também registre o relacionamento entre um cavalciro c uma fada, tem por cixo condutor as peripécias do cavalciro, as quais terminam por levá-lo ao Outro Mundo feérico. Assim, terá para estc estudo um valor essencialmente indicativo no (pue se refere ìs crenças ligadas ao Outro Mundo. O "Lai de Yonec", de Maric de Irance, e o "lai" anônimo de 'lyydorel, embora se enquadrem na categoria de "lais" feéricos, invertem o padrão supra citado ao colocarem cm cena uma mullher mortal que se cnvolve com um cavaleiro fećrico, motivo pelo qual não serão objeto de exames detalhados neste artigo.

O csforço de comprecnsão c análise das relaçōes que se cstabelecem entre o cavalciro e a fada nos "lais" fećricos só pode ser corretanente empreendido, a nosso ver; tomando por base duas constataçöes de caráter geral. A primeira delas, hoje um ponto pacílico entre cstudiosos do assunto, $\mathfrak{c}$ que as fadas presentes na literatura medieval $\mathrm{cm}$ língua vulgar derivam das mulheres do Outro Mundo dos mitos e sagals célticos. listas últimas podem ser delinidas como divindarles ou semi-divindades de caráter local, que mantêm relaçöes carnais com deuses ou homens dentro de padrōes e objetivos específicos, que vão se delineando ao correr da própria estrutura narrativa dos mitos c lendas celtas que chegaram até nós. Não é intençāo deste estudo discutir em riqueza de detallıes os relatos celtas galeses ou irlandeses, mas torna-se imprescindivel frisar desde já duas carac- 


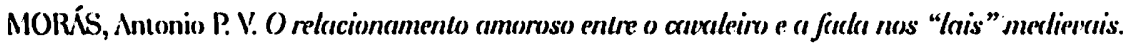

tcrísticas essenciais destes relatos: toda vez que uma mulher fećrica aparccer diante de um deus celta ou de um mortal, uma relação carnal decorrcrá destc cncontro, de forma a constituir um padrāo hicrogâmico; c normalmentc ć a mulher fećrica que toma a iniciativa da rclação. A imagem da fada que aparece na borda de uma fontc ou de um rio nos "lais" fcéricos ć extraída das lendas celtas que circulam oralmente durante a Idade Média. Este fato pode ser comprovado sem dificuldade pelo exame de textos célticos como "A destruição da hospedaria de Da Derga", que sc inicia precisamente com a aparição de uma mulher do Outro Mundo nas margens de uma nascente onde passava o rei Echu. lechu propōe-lhe sem rodcios, atravćs de um mensagciro, que cles durmam juntos, c a mulher do "Sid" (o Outro Mundo dos ccltas) afirma-lhe que ć por cstc motivo que tinha vindo (Cantz J., 1981:61-63).

Ncsta lenda irlandesa, rcplcta de refcrências míticas, toda uma progenitura real vai se formando a partir da união entre os descendentes do rei c os scres fećricos. Mas mesmo nos casos $\mathrm{cm}$ que a aparição da mulher do Outro Mundo não'tem por objetivo a constituição de uma progenitura rcal, o acasalamento da mulher fećrica com o mortal acaba se realizando ou, pelo menos, tem plenas condições de se realizar: No cnredo de "A docnça de Cuchulain", o herới Cuchulain só não fica com land, a mulher que o levou atć o Outro Mundo, porque cle já cra casado com Emer c, sc permanccessc com land, acabaria por viver no "Sid", afastando-sc assim do papel de "herói da tribo" que as lendas irlandesas lhe rescrvam (Cantz J., 1981:155-178).

As mulheres do Outro Mundo são scmpre descritas em trajes de luxo c portando objetos suntuosos, pois o Outro Mundo ć um lugar de riquczas c prazcres inigualávcis. Ém vistả das cvidentes analogias, ć difícil não pensar nos objetos de valor que acompanham as fadas nos "lais" medicvais, como as vestes luxuosas da fada no "l」ai de Craclent", o rico pavilhão da fada que se cnamora de l_anval no "I_ai de I_anval", c as bacias de ouro das damas de companhia da fada no "I Jai de Desiré". Pode-se concluir" 
Revista da ANPOHJ, , n" 5, p. 11-35, jul.//le\%.. 1998

deste fato que nem as características assumidas pelas fadas nos "lais", nem as formas c imagens com que clas são descritas nestas obras, são realmente originais. Mesmo as damas de companhia que rodciam as fadas parecem ser inspiradas no detalhe de que muitas vezes as mulheres do Outro Mundo manifestam-sc acompanhadas neste mundo.

A scgunda constatação de caráter geral concernentc aos "lais" medicvais ć uma decorrência da primcira, mas foi menos obscrvada pclos cstudiosos da litcratura medicval. Uma vez que em princípio os "lais" cram breves relatos cantados, de origem bretã, que desenvolviam temas fundamentados nas tradições célticas, é lícito supor que o enredo c o argumento dos "lais" medievais são, numa cxtensão variável, um desdobramento de antigos relatos de fundo céltico adaptados aos gostos, normas c valores do meio cortesão da scgunda metade do século XII em diante.

As constatações de caráter geral supra mencionadas aparecem com maior niticlez precisamente nos detalhes que cercam a manifestação da fada c nas nuanças do relacionamento amoroso que se cstabelece entre cla e o cavalciro. Pode-se comprová-lo cxaminando o "I_ai de I_anval", de Maric de France, e em seguida os "lais" anônimos de Graclent e Desirć.

Segundo a narrativa de Maric de lirance, l anval, o personagem principal do "lai" homônimo, ć um cavalciro deixado de lado nas liberalidades com que o rei beneficia scus demais cavalciros. Lim conseqüência do fato, l anval sai em cavalgada sozinho e preocupado, pois de acordo com o texto ele havia dispensado todos os seus bens, já que o rei nada lhe deu ("Tùt son aveir a despendu"). Scrá na condição de provedora das riquezas do Outro Mundo que a fada se revelará a l sanval.

Na margem de um rio, nosso herói desmonta. Scu cavalo ć acometido de um estremecimento violento e cle o solta pelo prado. Após deitar-sc no chão, "lunval olla abaixo, para o rio" ("guarda a vallez la rivicre"), c vê duas jovens ricamente vestidas, que vieram para levá-lo até o pavilhão cm que se encontrava sua senhora, estacionado bem nas proximidades ("Vecz, prest est sis pavelluns!") (I larf-I_ancner I., 1990):137-139). 


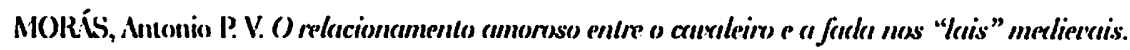

Obscrve-sc que o agcnciamento da narrativa organiza-sc intciramente $\mathrm{cm}$ torno do rio. Lanval desmonta quando se encontra em suas margens; scu cavalo tem um estremecimento misterioso e ele o libera de suas rédeas; cle deita-sc no chão c ao olhar para baixo, na direçño do rio, vê chegar as duas mensageiras da fada. Muito provavelmente isto ocorre: porque, nos mitos c lendas célticos, o fundo das águas ć uma das entradas para o Outro Mundo. Maric de France ainda reforça a alusão às riquezás do Outro Mundo ao afirmar que o pavilhão da fada é tão mairavilhosamente belo que "nenhum rei da terra teria podido comprá-lo" ("suz, cicl n'a reis kis clijast"). A própria menção de que luanval olha para baixo na direção do rio não deixa de comportar certa ambiguiidade, pois bem pode scr que no relato bretão original o cavalciro tenha visto as mensageiras da fada saírem de dentro do rio. lèm alguns contos célticos ivlandeses, o mortal encontra a fada debaixo d'água, como na história das aventuras do rei Ruadh na Terra Sobre a Onda, na qual o protagonista mergulha no mar para descobrir que mistcrioso cncantamento retinha sua cmbarcação e adentra pela 'lerra Sobre a Onda (um dos designativos do Outro Mundo céltico), chegando a acasalar-sc com uma mulher fećrica (Jackson K. II., 1971:150-151). Esta hipótese também acha-se corroborada pelo fato de que no "Isai de Craclent", que mantén praticamente o mesmo enredo que o "I ai de taanval", a referência ao fundo das águas como local de residência da fada aparece de forma explícita, conforme veremos mais adiante.

A descrição do primeiro encontro entre Lanval e a fála também se revela plena de significados. Quando o cavalciro é levado até o pavilhão da fada, esta se declara apaixonada por cle e diz que, se cle se mostrasse valoroso e cortês ("pruz c curtcis"), cla o amaria. I Aanval, por sua vez, entāo completamente fascinado pela beleza da jovem, the responde que, se cle tivesse a alegria de ser amado por cla, faria tudo o que pudesse para obedecê-la. I Logo a seguir; a fada concede scu amor a I Lanval e lhe diz que The fornecerá toda a riqueza que descjar: Após a jovem ter prevenido l_anval para que nāo mencionasse sua cxistência a ninguém, caso cm que a perde:- 
Revister de ANPOL/, 11" 5, p. 11-35, jul./1l\%\%, 19988

ria para sempre, o texto prossegue declarando que l_anval se deita junto a cla na cama ("Dclcz li s'est cl lit culchicz"), c lá permanece até a noitc (I-larf-I_ancner Iد., 1990:139-143).

Pode-sc notar que a iniciativa do relacionamento amoroso pertence intciramente à fada. lí cla que cnvia suas mensagciras para buscar o cavaleiro e depois the declara seu amor: Is no cncadeamento do relato, cncontra-sc uma das idéias que são caras a Maric de lrance: o amor deve ser mutuamente consentido entrc os amantes. E por isto que a fada afirma que amaria l_anval desde que ele se mostrasse valoroso c cortês, $\mathrm{c}$ l_anval lhe responde que a serviria em tudo rue pudesse. A necessidade de consentimento de ambas as partes é realçada em outras obras de Maric de lìance, como os "lais" de Yoncc, Cuigemar c líquitain, para citar apenas os três em que o consentimento amoroso envolve uma dúvida da parte da dama3.

O que é importante destacar é que o "l ‘ai de Lanval" revela um trabalho - conscientc - de claboração c ajustamento de antigos substratos míticos da parte da autora. 'lais substratos míticos, ao que tudo indica, mantiveram sua vitalidade ao screm absorvidos pela cultura folclórica medicval. Voltemos à caractcrização da mulher fećrica no relato lendário "A destruição da hospedaria de Da Derga" citado mais acima. Ela aparece ricamente vestida c adornada de jóias na margem de uma nascente. Echu propõc, por um mensageiro, que eles durmam juntos, c cla lhe diz textualmente que ć por isto mesmo que veio. lista é uma característica comum das mulheres do Outro Mundo que se mostram a um mortal nos mitos c sagas célticos: o scu próprio aparccimento diante de um mortal já assinala que o mesmo foi clcito para scr scu parcciro, o que implica incquivocamente um acasalamento cntre ambos. Isto não se verifica apenas cm relação aos mortais. No ciclo mitológico da lrlanda, Dagda, um dos principais deuses celtas, cncontra a Morrigan, uma deidade ligada à mortc c à carni-

(3) Os "lais" de Yonec, Guigemar e Equitain encontram-se em Harf-Lancner L., 1990:183209; 27-71 e 73-87, respectivamente. 
MORĹS, Antonio P. V. O relucionamento amorreso entre o cavaleiro e a fuctu nos "lais" medieveris.

ficina das guerras, nas margens do rio Unius e deita-se com cla, pelo que cla prometc auxiliar a tribo de Dagda contra scus inimigos na ocasião ${ }^{+}$. Mesmo quando estes relatos de fundo céltico aparecem recondicionados sob forma de contos, o modelo ainda segue tendo validade. No "Mabinogi", colcção de contos de origem galesa que circularam pela Brctanha francesa na Idade Média, Prvyll, um príncipe do sul de Cales, de cima de um outciro (os outciros, assim como as águas, são uma das cntradas do "Sid" nos mitos ccltas) avista Rhiannon, uma rainha do Outro Mundo c, quando csta se deixa alcançar por cle, cla lhe declara que é por causa dele que veio (Cirlot V., 1988:12-13).

Outros excmplos ainda poderiam ser arrolados aqui, mas seria cair cm redundância. Os dados colctados acima já nos permitem concluir que a manifestação das mulheres fećricas nos mitos e lendas célticos, c sua subseqüentc união com um personagem masculino mítico ou lendário cfetiva-sc dentro de um padrão cstruturado de significados, onde a aparição da fada diante de uma fonte d'água ou de um outciro, adornada com roupas c objetos de valor c exatamente num local de passagem de um personagem masculino já é um indicativo: a) de que cla é de fato uma mulher do Outro Mundo; b) de que o personagem masculino a quem cla se mostrou é justamente o escolhido para ser scu parceiro; e c) de que o resultado esperado deste encontro é a união (scxual e muitas vezes também matrimonial) dos parcciros, com conscquiências que variam conforme a narrativa encarada.

O padrão hicrogâmico assim representado revcla-sc consistente precisamentc por constituir uma estrutura de significados codificados $\mathrm{cm}$ nível simbólico c perfeitamentc inteligívcis. Hipotcticamentc falando, um celta que cscutasse com certa reverência os mitos de sua comunidade ou se divertissc ouvindo as histórias c lendas prescrvadas por scu povo não nccessitaria de maiores explicações a respeito das mulheres do Outro Mundo

(4) O episódio acha-se relatado em Sjoestedt M. -L., 1940:56 e também em Vries J., 1963: 238. 
c sua forma de relacionar-se com os deuses ou mortais, pois o significado destes episódios se configuraria claro para cle. De modo análogo, o meio rural medicval reteria antigos contos c lendas legados por suas tradições folclóricas, desconsiderando qualquer esforço de claboração ou refinamento dos mesmos, pois cles se averiguariam atuantes justamente nos termos de uma oralidade que remete a um saber tradicional ligado ao hábito de contar velhas histórias, capazes de relacionar o passado ao presente vivido pela comunidade rural c, também, de revitalizar as crenças sustentadas por esta mesma comunidade (a crença nas fadas persistiu no mcio rural curopcu até o início do século $X X$, se não depois). Contudo, ao screm acondicionados numa forma litcrária (o que pressupōe um trabalho crítico c consciente de um autor preocupado $\mathrm{cm}$ dar consistência c clareza ao seu cscrito), direcionada a um ambiente socialmente restrito na Idade Média (o meio cortesão constituído por cavalciros c clérigos instruídos), os antigos relatos lendários bretões sofiem inapclavelmente um processo de adequação às idćias, valores c idcais propagados neste ambiente, que ć cxatamente o meio $\mathrm{cm}$ que trafegou Maric de lirance ao se radicar na corte inglesa, cspaço receptivo aos indivíduos de instrução mais apurada desde a ascensão ao trono de I lemrique II Plantagenct.

Maric de Hance, no "Lai de Lanval", não deixa de reproduzir as concepçōes, ideais e valores que vão ganhando terreno no meio cortesão. Voltemos ao cncontro do cavalciro e da fada conforme citado. Quando se declara a Isanval, a fada lhe diz textualmente que, se ele for valoroso c cortês, nem imperador; nem conde e nem rei poderão pretender a felicidade que cle terá:

\footnotetext{
"emperear: ne quens ne reis

not unkes tant joie: ne: bien" (I larf-I.anener I.., 1990:1+1).
}

A passagcm já insinua que a fada sc achava num patamar social supcrior ao de l_anval e podcria perfeitamente ser amada por membros dos cstratos mais clevados da sociedade feuclal. A supcrioridade da fada 


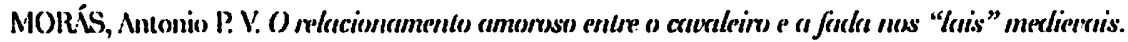

cm relação aos cavalciros cstacionados na cortc do rei Arthur vê-sc confirmada na parte final do "lai". Lanval incorre no ódio da rainha por ter repelido suas propostas de amor, c cla o acusa perante o rei de tê-la ofendido. A fada então resolve aparecer diante da corte para defender I _anval. No cntanto, sua cntrada é precedida por duas visitas consccutivas de suas damas de honra, que saúdam o rei Arthur e pedem-lhe que preparc aposentos adequados para sua senhora. lí só após csta afirmação de sua precminência que o texto retrata a fada dignando-se a aparecer diante de Arhur; ostentando scus adornos riquíssimos e sua beleza sem par; apenas para provar que l sanval não mentiu quando afirmou que cla c suas acompanhantes cram mais belas do que a rainha, retirando-se logo $\mathrm{cm}$ scguida (I larf-I_ancner I.., 1990:159-167). Destc modo, o texto de Maric de lirance representa a diferença fundamental entre os amantes, a diferença de natureza (que ccrtamentc cra a questão principal nos antigos "lais" bretãos), associando-a à desigualdade de condição social c cconômica que se verifica cntre luanval c a fada.

A penctração das concepções, idcais c valores que vão se definindo a partir do ambiente cortesão também se revela no uso da palavra "cortês" por parte da fada. Nas canções de gesta, muitas delas antcriorcs aos "lais" de Maric de lirance, o termo "curtcis" designava simplesmente as qualidades do cavalciro criado na cortc $\mathrm{c}$ atento às normas de conduta vigentes cntre os cavaleiros, não se referindo a nenhuma polidez, ou deferência especial para com as damas ('Frappicr J., 1959:135-137), scntido que cstá implícito no "I aai de L Lanval": o herói deve saber comportar-sc, sc descja o amor da fada. Lsta idéia é ainda reforçada na sequiência do texto. Depois de permanecer no leito atć a noite com a jovem (sugestão de que houve a união sexual do casal, que é mencionada de forma incquívoca nos mitos c lendas celtas c também nos "lais" anônimos de Craclent c Desiré), I_anval partc a pedido dela, após receber ricas vestimentas que muito o cmbelczàm. L nem de um rústico" ("n'cstcit mic fols ne vilcins"). Aqui já se obscrva uma 
afirmação das atitudes que se ligam ao ideal de cortesia cavalcircsca, que mesmo cvocado cm alguns textos da época, não sc achava plenamente definiclo nem em termos de uniformidade literária, nem em termos de uma ctiqueta de corte denotativa de um cstilo de vida professado $\mathrm{cm}$ larga cscala pelas elites laicas da socicdade feudal". É também provável que: Maric de France tenha empregado o termo "rústico" ("vilcins"), associando-o a uma conduta imprópria diante da fada, porque nas lendas bretãs de fundo céltico o rclacionamento da mulher fećrica com o mortal comportava uma crucza c uma ambigüidade sinuosa que destoavam completamente do modelo do "fin'amors" que cntão começava a assentar-se no norte da liuropa vindo do l sangucdocjuc. As aparentes incongruências do envolvimento da mulher fećrica com um mortal cram uma das caractcrísticas fundamentais dos mitos c lendas célticos, tendo-sc mantido suficientemente ativas para serem representadas nos "lais" anônimos examinados em seguida, os quais achavam-se mais próximos da cultura folclórica do que os "lais" de Maric de lirance.

Antes de prosseguirmos, cabe fazer uma obscrvação sobrc os "lais" cm geral, muito pertinente no caso dos "lais" fcéricos. Como J. C. Payen já notara, a ćtica do "fin'amors" ć incompativel com a sobricdade narrativa do "lai", c os autores que tentaram adequá-lo aos refinamentos da "courtoisic", como Jcan Renart no "I aai de l'Ombre", não deixaram de desnaturalizar o gênero (Jodogne O. et Payen J. C., 1975:53). É incgável a justeza da afirmação de Payen, c pode-se mesmo falar; como cle o faz, numa "polseza" idcológica de Maric de lrance, cuja obra não adere a uma perspectiva cortesã nem anti-cortesã c volta-sc apenas para a objeti-

(5) Não creio que se deva ver no amor cortês um modelo de comportamento geral validade no ambientc cortesāo e arraigado em termos de padrōes de conduta. É mais plausível supor que se trate de um jogo sutil e leveinente crótico, que exige a presença das damas e jamais chegou a firmar-se $\mathrm{cm}$ termos de consenso ou uniformidade. É sintomático, aliás, que Joinville, nos tempos do rei S. Luís, recupere uma associação entre o romance cortês e a literatura para "os aposentos das damas" mencionada por um nobre (Frappier J., 1959:136). 


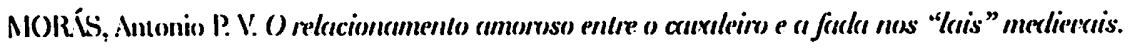

vidade da narrativa (Jodogne O. et Payen J. C., 1975:40). Independentemente do fato de o "lai" constituir um gêncro narrativo que prima pela sobricdade c pela objetividade, parece-me que a inadequação entre o ideal do amor cortĉs c o argumento dos "lais" $\mathrm{cm}$ geral não se prende apenas a questốcs de ordem formal. O próprio conteúdo destes cscritos, ao se reportar constantemente a um fundo cultural céltico, arcaico nos termos das concepçõcs e valores vigentes no mcio cortesão, atua no sentido de incompatibilizar a ćtica do "fin'amors" com os desdobramentos narrativos dos "lais", como o pode demonstrar o "Lai de Craclent".

Em linhas gerais, o "Lai de Craclent" mantém o mesmo enredo que o "L_ai de Lanval": um cavaleiro que não ć contemplado pelas benesscs de um rei envolve-se com uma fada, que the fornece bens c riquezas, e rejcita as propostas amorosas da rainha, incorrendo $\mathrm{cm}$ seu ódio. A diferença entre ambos é que no "Craclent" o papel da rainha acha-sc ampliado. Ela declara scu amor a Graclent já na abertura do "lai", c é cla que faz com que o rei não o recompensc. J. C. Payen parece admitir a antigüidade dos "lais" de Craclent c Cuingamor; mas a sc julgar pelas refcrências contidas no "Craclent", sua redação não deve ser anterior ao final do século XIIinício do século XIII, não apenas porque as dificuldades cconômicas cotidianas do cavalciro são descritas com notávcl realismo, como também pclo fato de clas screm contrapostas ao mundo do burguĉs abastado que vive nas cidades. No "L Lai de Lanval", o protagonista, mesmo sendo um cavaIciro agregado à corte do rei Arthur, é designado como fillho de rei. Craclent, no "lai" que porta scu nome, é definido como um simples cavaleiro contratado pclo rei ("saudoicrs"). Quando o rei retém scu soldo, cle é obrigado a pôr $\mathrm{cm}$ caução scu velho cavalo, não podendo abandonar a cidade. I lospedado na residência de um burguĉs, Craclent certo dia ć dcixado sozinho na casa, cuando o casal de anfitriôes vai comer na casa de amigos do burgo. A filha do casal de burgueses, que também ficou na casa, amavelmente o convida a jantar com cla, porém Craclent decide sair a cavalo. Chama scu cscudciro para que prepare sua montaria mas, infelizmente, 
cle já não tinha mais cela. A jovem então, de boa vontade, lhe cmpresta cela c arrcios. Craclent atravessa o burgo para ir à floresta usando uma vestimenta de peles bastante gasta c é objeto de riso do populacho. O texto afirma que estc ć o costume do burguês, que não sabe ser cortês:

\footnotetext{
"Tex est costume de borgois

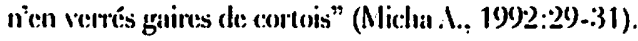

É cvidente o desamparo de Craclent numa sociedade em que a posse de bens c a companhia de seus pares sĩo as marcas de reconhecimento do prestígio dos indivíduos. Depois do episódio do encontro entre Craclent c a fada, c após ele receber de um mensagciro dela os meios de saldar todas as suas dívidas c pagar seu hospedeiro, o texto declara que este último cra um homem valoroso, cortês e pleno de qualidades para um burguĉs:

"I i hostes fu prox e cortois
o molt vaillans comme borgois" (Nicha i., 199:2:+1).

É clifícil fugir à conclusão de que o "Lai de Craclent" foi cscrito para um público cortesão acrescido de elementos saídos da burguesia abastada das cidades, que se misturavam às cortes principescas e tentavam assimilar os modos c atitudes cortesãos; daí a distinção entre a arraia-miúda que escarnecia de Craclent $\mathrm{c}$ os termos cavaleirescos utilizados para clogiar scu hospedciro. De todo modo, os referenciais do mundo burguĉs são uma constante cm todo o "Iدai de Craclent".

O encontro de Craclent com a fada ć um cpisódio repleto de significados. Saindo para cavalgar, Craclent adentra numa floresta atravessada por um rio. Uma corça totalmente brancia salta a sua frente $\mathrm{c}$ cle a perseguc, sendo conduzido a uma fonte de águas claras, onde uma jovem se banhava servida por duas outras jovens, que se mantinham nas margens da fontc. Scduzido pela belcza da fada, Craclent resolve retê-la guardando suas roupas, que estavam sobre uma ramagem. Mas a jovem o interpela em cólera c lhe ordena que devolva suas roupas. Sc ele quisesse, poderia 
MOR.S, Antonio P. V. O relacionamento amorosso entre o auvaleiro e a fucta nos "(nis" medievcris.

ficar com scu manto, que alcançaria um bom preço por sua qualidade. Craclent lhe responde que não cra filho de mercador nem de burguĉs para vender mantos (novamentc uma refcrência ao mundo burguês). Ele lhe diz para sair da água. Percebendo que cle permaneceria ali retendo suas roupas, a fada sai após ter obtido delc a promessa de que não lhe faria mal algum. Ela sai da água c obtém suas roupas. Craclent a lcva para longc das outras jovens c lhe solicita scu amor; querendo fazer dela sua amiga:

"d'anior l'a requise e proiic

et que de lui face son dru".

A fada the responde dizendo-sc espantada com sua ousadia, pois nenhum homem da posição dele convém a uma mulher de sua linhagem:

"ja n'alicert pas a ton parage:

nule fenme de nom lignage" (Nicha $\Lambda ., 1992: 34)$.

A transformação da diferença de natureza entre o cavalciro c a facla numa diferença de nível social, insinuada no "Laai de I _anval", manifestasc agora de forma incquívoca. Vendo que nada conseguiria dela, Graclent a leva para o mais profundo da floresta c a toma pela força. Depois, cle roga docemente para que cla não scja rigorosa c lhe conceda scu amor; pois cle fará dela sua amiga c a amará ficlmente. $O$ texto diz $\mathrm{cm}$ seguida que a jovem vê que Craclent cra cortês c sábio ("cortois c sages"), alćm de bom cavalciro, c lhe concede scu amor (Micha A., 1992:36).

Devemos nos precaver de uma comprecnsão incorreta desta passagem. Ph. Mćnard, que vcrificou a importância crescente da declaração amorosa na litcratura arturiana (Mćnard Ph., 1970:33-42), afirma cque os "lais" anônimos conscrvam velhos temas de origem celta, o que é correto, mas diz $\mathrm{cm}$ seguida que nestes cscritos a fada recusa ceder à violência $\mathrm{c}$ não sc entrega ao cavalciro que desdenha obter seu consentimento, dentro de uma mistura "de dissimulação, de pudor c de coffuctismo" (Ménarel Ph., 1970:35). Ora, não ć isto quc ocorrc no "lai" cm questão. Craclent 


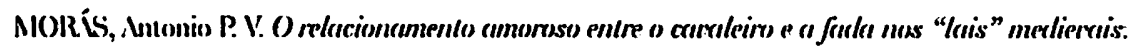

indivíduos que ganhavam a vida contando suas histórias oralmente, as quais remetiam necessariamente ao rescrvatório de tradições, concepçōes c crenças conservado pela cultura folclórica. Ĺ a vitalidade c a cocrência de que dispõc o folclore no mundo rural da Idade Média, aliadas à incxistência de estratćgias de sclcção c desqualificação da cultura oral, que cxplicam porque o "I _ai de Craclent", de data posterior ao "I _ai de L_anval", descreve com maior realismo as dificuldades econômicas do herói e, ao mesmo tempo, mantém-se mais ficl a crenças e concepçōes folclólicats de cunho arcaico".

Os substratos arcaicos ligados ao mundo fećrico também sc manifestam num outro detalhe do encontro entre o cavalciro e a fada no "Iai de Craclent". O protagonista encontra uma corça branca na floresta c, ao persegui-la, é levado até a fada que se banhava na fonte. A corça brancá, no presente caso, é o animal cuja função ć conduzir o cavalciro até onde a fada se encontra, normalmente um veio d'água, mas, algumas vezes, um reino localizado no Outro Mundo. F́ o rue ocorre, por exemplo, no "I aai de ('uingamor", onde o protagonista sai à caça de um fabuloso javali branco c, perseguindo-o pela floresta, chega num palácio que descobrirá pertencer à fada. Continuando no cncalço do animal, cle topa com a própria fada, que mais uma vez ć retratada banhando-sc numa fonte (Micha A., 1992:83-89).

As crenças arcaicas ligadas ìs fadas manifestam-sc ainda no desenlace do "I ai de Craclent", num detalhe que foi desnaturalizado no "I دai de I _anval" de Maric de lirance. Como neste "lai", a fada do "I_ai de Craclent" aparcec diante da corte para provar que Craclent não mentiu quando

(b) Esta selecão qualitativa manifesta-se abertaınente nos dias atuais. Em nosso senso comum, o folclore é entendido como um resquício de crenças e costumes ultrapassados c antiquados, c as práticas folclóricas só ganham espaço nos meios de comunicação por seus aspectos convencionais ou pelo exotismo das crenças professadas. Quase nunca ele c analisado pelo ângulo de um processo de legitimação de uma cultura erudita "oficial" que desqualifica os sistemas culturais ditos "populares". 
Revistu da ANPOIJ,, n" 5, p. 11-35, jul./de\%., 1998

disse que tinha uma amiga mais bela do que a rainha, retirando-se logo en seguida. Graclent pede a permissão do rei c sai cavalgando atrás dela. A fada chega ao rio, que nascia da fonte onde cla foi achada, c mergulha nele com seu palafiém e suas companheiras, tendo alertado Craclent de que cle acabaria por se afogar se lá entrasse. Craclent seguc-a assim mesmo e quase se afoga, sendo salvo pela fada, que puxa scu cavalo pelas rédcas atć a margem c retorna ao rio. Mas o cavalciro insistc c torna a mergulhar; perdendo scu cavalo na corrente. Quando ele estava a ponto de sc afogar; as companhciras da fada suplicaram-lhe para que cla o salvasse. A fada cntão, compadecida, lcva-o com cla até o scu mundo (Micha A., 1992:57-61). Já no "I دai de l sanval", o protagonista cspera pela fada na cscadaria de mármore colocada na saída para auxiliar os cavalciros a montar c, quando a fada sobe $\mathrm{cm}$ scu palafrém, l anval salta atrás dela c scguc com cla até Avalon, no Outro Mundo (I larf-L_ancencr Iد., 1990:167).

Sc é verdade que os "lais" de Maric de France revelam-se mais claborados c originais ao adequar scu enredo às convençōes da vida da corte, ć também incgável que csta claboração muitas vezes se rcaliza à custa de um empobrecimento do sentido e dos desdobramentos da ação presentes nos relatos génuinamente bretãos, tributários dos mitos c lendas célticos. Assim como atenuou a relação carnal entre Lanval c a fada ao colocá-los deitando-se um ao lado do outro no leito, Maric de France apagou outra unidade de significado estruturado relacionada ao envolvimento da fada com o mortal. Com efeito, este último só pode cntrar de fato no reino do Outro Mundo se a fada o conduzir até lá. É por isto que Graclent se teria afogado no rio se a fada não o auxiliasse e consentissc $\mathrm{cm}$ levá-lo até o seu mundo. li o "l_ai de Cuingamor", onde o cavalciro é retratado penctrando no Outro Mundo, não perfaz uma exceşão. Cuingamor realmente chega ao palácio da fada, mas ele o encontra descrto, não vendo viva alma por perto. Segue então a pista do javali c dá de encontro com a fada na fonte, que lhe diz que ele jamais capturará esse animal sem sua ajuda (pois se trata de um animal do Outro Mundo). Após comprometer-se a ajudá-lo, 


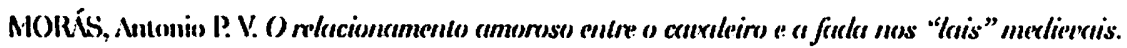

cla o leva de volta ao palácio, c cntão Cuingamor o vê repleto de habitantes do Outro Mundo e de cavalciros que antes dele saíram para caçar o javali e jamais retornaram (Micha A., 1992:85-93). O mesmo complexo de noçöes acha-se representado no "Laai de Desiré". Desiré, que mantém um relacionamento de anos com a fada, um dia encontra um anão enviado por cla para scrvi-lo, enquanto cle cstava no meio da floresta. Desobedecendo às ordens da fada, o anão o conduz até o palácio onde cla vivia. Ao tentar entrar nos aposentos de sua amiga, Desirć tropeça c atrai a atenção da guarda do palácio, sendo salvo por uma acompanhante da fada com quem travara contato anteriormente, a qual the afirma que, se os guardas o tivessem apanhado, cle teria sido morto (Micha A., 1992: 139-143)?

Ėmbora este episódio do "Lai de Desirć" já assinale uma tentativa de adequar o Outro Mundo cético aos modelos de castelos fortificados da Idade Média, as noçôcs relativas à entrada do mortal no Outro Mundo permanecem atuantes cm todo o "lai": quando tenta seguir o fillho que teve com a fada até o Outro Mundo, Desiré se perde na floresta. Encontrando o anão, cle tenta chegar ao castclo da fada, mas sem sucesso. Só quando a fada o leva para viver com cla é que ele penctra de fato no Outro Mundo.

O "Iدai de Lanval" c o "Laai de Craclent" não deixam de ter uma dimensão escapista. Seus personagens principais só conseguem equilibrarse neste mundo com os recursos vindos de um ente sobrenatural, e seu amor por esta mulher fabulosa pode se realizar apenas no Outro Mundo. Não devemos supor, contudo, que as fadas presentes nos "lais" medicvais se enquadrem dentro de um modelo comum, voltado a uma literatura de

(n) Este complexo de idéias acha-se em perfeita sintonia com os mitos e lendas celtas recoIhidos nos textos galeses $\mathrm{e}$ irlandeses. Nestas narrativas, não apenas a fada é quem assegura a ida do herói até o Outro Mundo como, em muitos casos, a iniciativa das açōes que ocorrem no Outro Mundo pertence a ela. 
Revista cke $A N P O / J$, , n" 5, p. 11-35, jul./dle\%,, 1998

finalidade compensatória cm termos psicológicos. Com certcza, no "Lai de Desiréc" não ć isto que ocorre. Neste "lai", a fada parece ser uma descendente direta das semi-divindades célticas ligadas a locais específicos. 'Todas as apariçōes da fada dão-se na Charneca Branca ("Blanchc l_ande"), na região de Calatir, na Escócia. É nesta localidade que Desirć nasceu, c sempre que descja encontrar-se com a fada cle desloca-se até a floresta vizinha à Charneca Branca. Por sua vez, o rei da liscócia, suscrano de Desiré, é visitado pela fada c scus fillos quando se cncontrava cm Calatir.

Uima outra característica do cnredo destc "lai" ć o contraponto obscrvado cntrc os referenciais cristãos e aqueles do mundo fećrico. Os pais de Desiré não conseguem ter fillhos, por isto fazcm uma percgrinação até o santuário de St. Ciles, na Provence. Graças ao santo, cles têm um filho, Desirć ("Descjado"), mas ć a fada que continuará a descendência da linhagem, ao ter um casal de filhos de Desirć. Ao lado da floresta habitada pela fada c suas acompanhantes achava-sc um cremitério, onde Desiré costumava confessar-sc ao cremita, c é justamente por confessar ao mesmo suas relações com a fada que Desiré sc indispōe com cla, quase chegando a perdê-la. No rclato, os dois parcciros mantêm sua rclação por décadas, até que scus filhos atinjam a maioridade, c só cntão a fada manifesta o descjo de se unir matrimonialmente a Desiré, antes de levá-lo ao scu mundo. Incgavelmente, o cnredo deste "lai" já insinua uma desconfiança a respcito da naturcza das fadas.

Ciomo se dá o encontro entre Desirć c a fada? limbora adequandosc às linhas gerais dos exemplos supra citados, o "lai" em questão decora o cpisódio com alguns detallhes particulares. Desiré, que visitava scus pais durantc uma curta ausência da corte, decide ver o cremita, mas no caminho encontra uma bela jovem, que se dirige a uma fontc carregando duas bacias de ouro. Desirć resolve tomar a jovem para "fazcr dela sua amiga" ("il cn vodra fere s'amic"), mas a jovem lhe diz que acompanhava a mais bcla dama do mundo c que poderia lcvá-lo atć cla, mas que cle deveria tomar cuidado para não dcixá-la cscapar; pois se cle a possuíssc, tcria ouro 


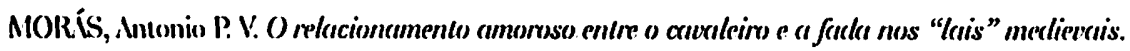

c prata $\mathrm{cm}$ abundância c tudo quanto descjasse. lì se acaso sua senhora não lhe conviesse, cla faria tudo o que lhe desse prazer ("jo ferai tut vostc plcisir"), terminando por lhe dizer que o ajudaria em toda necessidade ("aidcrai vus a grant bosoing"). Intcressado no acordo proposto pela jovem, Desirć solta-a c scguc-a atć onde a fada pcrmanccia com outra companhcira. Ao vê-lo chegar; a fada cmbrenha-sc na floresta, mas Desiré a alcança c lhe diz que cra um cavalciro desse país c que a serviria lealmente. Convencida por cstas palavras, a fada the concede scu amor c cle fica um longo momento com cla (Micha A., 1992:113-119).

As mesmas noçōes representadas nos "lais" anteriores repetem-se neste tcxto, porćm de forma particular: Desiré vê a dama de companhia da fada c quer "fazer dela sua amiga". Como no "Iدai de Craclent", fazcr de uma jovem sua amiga é um simples cufemismo para o ato sexual, pois o idcal do amor cortês não pode scr conciliado ao padrão hicrogâmico cstruturado cm nível simbólico descrito mais acima. Émbora o texto não o afirme catcgoricamentc, cstá implícito que Desiré sc deitou com a fada, scnão a jovem que encontrou na fonte não lhe teria dito que, se sua senhora nāo lhe interessasse, cla faria scu prazer: lis pode-se verificar que, neste "lai", a própria acompanhante da fada impcle o cavalciro a relacionar-se com sua senhora. Indubitavelmente csta dama de companhia, que não apenas leva o herói atć a fada como também o salva, no cpisódio supra citado de sua invasão ao castclo da fada por intermédio do anão, inspirase largamente em l_unctte, personagem do "Yvain" de Cihrétien de 'Thoyes. Nesta obra, Yvain é colocado a salvo dos guarda do castclo de Esclados o Vermclho graças a luuncttc (I-lult D. F., 1994:127-133), c toda uma cumplicidade se cstabelece entre ambos. É I unctte quem agencia o casamento cntre Yvain e sua senhora, a dama de I_anduc, e posteriormente Yvain bate-se $\mathrm{cm}$ duclo judicial por cla, a fím de provar sua boa fé (I lult D. F., 1994:401-415). Já ao final do romance, Yvain reconcilia-sc com a dama de I sanduc em virtude das artimanhas de luuncttc (I lult D. F., 1994:575583). Limbora a relação entre Desiré c a dama de companhia da fada não 
Reviska da ANPOOLL, n" 5, p. 11-35, jul./de\%,, 1998

sc ache tão desenvolvida no "lai", o fato de cla dizer ao cavalciro que o ajudaria $\mathrm{cm}$ toda necessidade, como se tivesse motivos para isso, só pode explicar-se pela influência do romance de Chrétien de 'lìoyes. Além disso, nas narrativas galesas ou irlandesas concernentes às mulheres do Outro Mundo, as acompanhantes da personagem principal não desempenham qualcquer papel ativo no desenvolvimento da trama.

É importante notar que a inclusão de motivos c situações oriundos do "Yvain", de Chréticn de 'Troyes, não obscurcce os substratos arcaicos que cmbasam este "lai" fcćrico. A acompanhante da fada apenas incita o cavalciro a possuir sua scnhora, cla não a predispõc a accitar o amor do mesmo ncm apara as diferenças entre ambos, como o faz lunette $\mathrm{cm}$ "Yvain". A relação carnal c o compromisso que se estabelece entre um mortal c uma scmi-divindade do Outro Mundo mantém-se inalterados no "lai" supra citado. E segundo as informaçōes possibilitadas pclo texto, certamente o "I sai de Desiré" ć postcrior ao "Yvain" de Chrćtien de 'Troyes, sendo composto, na melhor das hipóteses, no final do século XII". Ao que tudo indica, os "lais" de Maric de France o precederam por décadas. Isto não impede que cle sc mantenha mais próximo dos substratos arcaicos acondicionados na cultura folclórica do que o "L _ai de l_anval".

À guisa de cncerramento, valeria a pena recapitular as conclusões obtidas neste cstudo c ao mesmo tempo tentar estabelecer algumas linhas de análisc que possam facilitar a comprecensão global do problema tratado. Vimos que certas concepçōes relativas às mulheres do Outro Mundo, presentes nos mitos c lendas celtas, sobreviveram na cultura folclórica medicval $\mathrm{c}$ foram absorvidas pela literatura cortesã $\mathrm{cm}$ língua vulgar: lim última análisc, tais concepções mantiveram-sc atuantes porque sc achavam constituídas $\mathrm{cm}$ termos de estruturas de significado codificadas $\mathrm{cm}$ nível simbólico, c a consistência c a cocrência interna dos padrõcs assim

(8) É praticamente um consenso entre os estudiosos da literatura medieval que o "Roman de Yvain" foi composto entre 1175-1180 (ver Hult D. F., 1994:8). 


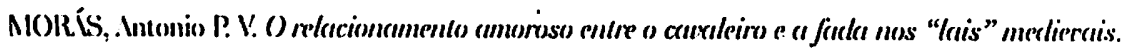

formados garantiram a reprodução dos mesmos, ainda que cles fossem por princípio incompatívcis com a ćtica do amor cortês. Por outro lado, a ética do "fin'mors" não deve scr encalada como um modclo acabado ou uniforme c muito menos como um componente inseparável da produção literária cortesã dos séculos XII-XIII. As canções de gresta tardias, devido a sua ênfase nas disputas c combates entre cavaleiros, relegaram a segundo plano ou francamente deixaram de lado os preccitos do amor cortês, assim como os "lais" jamais se adaptaram totalmente aos mesmos, tanto por" sua concisão narrativa, quanto pelo conteúdo arcaico de alguns deles, como é o caso dos "lais" fcéricos.

A dinânica das forças que interagem nas representações das faclas na produção literária cortesã assenta, numa cscala abrangente, sobre fatores rle ordem antropológica (referentes aos códligos e referenciais culturais em sentido extenso c aos níveis de cultura presentes na socicdade medieval), lingüística (a relação cntre o oral c o escrito) o também sobre questôcs de ordem sociológica relativas à compartimentação dos segmentos sociais no ambiente cortesão.

No que se refere à temática cultural, cabe enfatizar que os códigos simbólicos que definem as representações das fadas não existem apenas enquanto padrōes literários. Muito ao contrário, cles reproduzem-se no domínio literário justamente por sc acharem fundamentados no sistema de crenças c concepçōes da época. Na Idade Média, acreditava-se nas ládas dentro do aparato de concepgōes supra mencionado. Basta uma leitura das coletâneas de maravilhas confeccionadas no período, como o "De: Nugis Curialium", de Walter Map, c os "Otia Imperialia", de (Gervais de 'Tilbury, para comprová-lo. As fadas de origem céltica que se acasalam com os mortais, gerando-lhes descendentes ou fornecendo-llos riquezas e ascensão social, acham-se bem representadas nestas obras", c Cervais e

(') Ver, por exemplo, as histórias de Gwestin Gwestiniog c Eadric o Selvagem in Bate A. K., 1993:145-146 e 149-150, respertivamente. Para as fadas célticas de Gervais de Tilbury, ver Duchesne A., 1992:98 c 148-150. 
Reristu ckn ANPOLL, n" n, p. 11-35, jul./de\%., 1098

Tilbury tenta mesmo explicar sua existência associando-as às "larvas", demônios que assumem formas corpóreas para seduzir os homens ('lilbury C., 1992:98). Mas o fato ć que as fadas cram criaturas plausívcis para uma ampla parcela da população medieval, independente das conotações diabólicas que os clérigos tentaram impingir-lhes. Na realidade, é extremamente difícil reduzir as crenças e concepçôes relativas às fadas a um modelo literário único ou a um padrão cultural uniforme devido à larga difusão das mesmas.

Um outro fator çuc também interfere na definição das representaçōes das fadas ć a relação que sc cstabclece entre as narrativas orais c os textos cscritos no ambiente cortcsão, pois as cortes aristocráticas dos séculos XII c XIII achavam-sc abcrtas não só aos escritores providos de formação clerical (os quais muitas vezes cram patrocinados por nobres como Maric de Champagne c Philippe de Flandres), como também aos humildes jograis que contavam suas histórias $\mathrm{cm}$ troca de comida ou pecpuenas recompensas. No prólogo de "lìrec c Énide", Chréticn de 'lioyes já revela uma tomada de consciência de sua habilidade literária e do valor do texto escrito, ao declarar que de um conto de aventuras cle tira uma muito bela composição:

"Hi trait (d')u"l conte d'aventure une moult bele conjunture"

O autor acrescenta também que tal conto cra freqüentemente corrompido c reduzido ao cstado de fragmentos por aqueles que viviam de contar histórias diante de reis c condes:

"Que devant ris el devant contes

Depecier et corrompes stedent

(il rue de: conter vive vuelent" (Prit\%.J. -M1., 1992:283).

A atividade de contador de histórias revela-se com clareza em alguns escritos medicvais, como no próprio "Erec c Enide". Durante as festividades do casamento de Erec e Enide, realizado na corte de Arthur; os 
MORís, Antonio P. V. O relacionamenlo amoroso entre o cauxaleiru c a fack nos "lais" medietruis.

contadores de histórias aparecem associados aos músicos que sc aglomeram para divertir a scleta assembléia de convidados:

"i $\mathrm{j}$ uns conte, li autre chante:

I.j uns sible, li autres note:

(il sert de harpe, cil de rote" (Firits. J. -M., 1992:172).

Em "Aucassin et Nicolette", autêntica paródia das canções de gesta e dos romances cortesãos, Nicolettc, disfarçada de trovador; aparece diante da cortc presidida por scu amado Aucassin c narra-lhe a história de suas desventuras amorosas, que ć a história deles próprios (Dufournct J., 1984:155). listc cxpedientc litcrário, utilizado pelo autor para reconciliar os dois personagens, só faria sentido se o ambiente da corte fosse um espaço aberto aos contadores de histórias devotados ao entretenimento de uma audiência nobre.

Ressalta dos dados fornecidos pela própria litcratura do período que as cortes aristocráticas da $2^{n}$ metade do sćculo XII cm diante cram ambientes propícios a todo um entrecruzamento envolvendo contos c narrativas orais, a maioria deles cmbasados ou, no mínimo, receptivos às histórias c rclatos lendários do folclore, c obras litcrárias como os "lais" c os romances de cavalaria. Nesta linha de raciocínio, a própria distinção cntre a narrativa oral c a narrativa cscrita $\mathrm{cm}$ vernáculo na Idade Média não pode ser cncarada nos termos de categorias estanques, pois já se acha hoje estabelecido que os romances medicvais prestavam-sc tanto à leitura cquanto à cxposição oral diante de uma platéia (Grosby R., 1936:88-110), c os "lais" medicvais, por sua brevidade, ccrtamente adequavam-sc muito bem aos recursos da declamação. lí desnecessário dizcr que tudo isto facilitou a circulação c a prescrvação de uma gama bastante rica de concepçōes c representaçõcs arcaicas armazcnadas na cultura folclórica, muito particularmentc no caso das fadas.

RÉSUMUE: Le présent article analyse le poids des croyuncess et conceptions orriginaires de la cullure folklonrique, élablie dans les lermes d'unne orrelithe, ckuns la

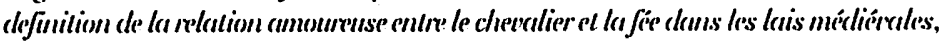

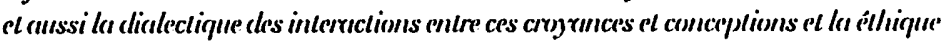


Revista da ANPOLL, n" 5, p. 11-35), jul./de\%., 1998

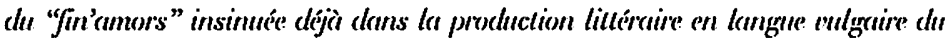
milieu du XIIr siècle.

MOTS-CLSS: Croyrences; conceptions, culture follilorique; orralité; dialectique des intercictions; álhique du "fin'unors"; prodhetion litlérnire.

\section{BIBLIOGRAFIA}

B.TTE, A. K.(199:3) Comles pour les gens de cour (trarl. do "De Nugis Curialium" de Walter Map); Belgique, Brepols.

CIRI.OTY, V.(1988) Mabinogion (trad. do "Mabinogi"); Madricl, Siruela.

CROSBY, R. (19:36)" (Oral delivery in the Middle Ages"; Spectulum, V. 11, p. 88-110.

DUCI IESNEL, A.(1992) Le live des merveilles (tracl. parcial dos "Otia Imperialia" de Cervais de Tillsery); Paris, Belles letures.

DUROURNET, J. (1984) Aluctessin et Nicolette (trarl.); Paris, (;F Flammarion.

FRUPPIIER, J. (1959) "Vutes sur les conceptions courtoisiss dans les littératures d'oce de d'oil aul XII" siècle"; Calicers de civilisalion módićucale, n. 2, avr-juin, p. 1355-156.

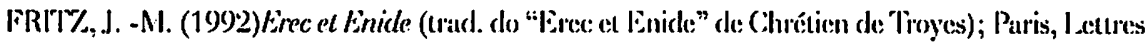
gothiques

C.WTY\%, J. (tratl.) (1981)Eauly Irish Myths and Sergers; I.omdon, Penguin.

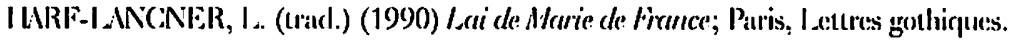

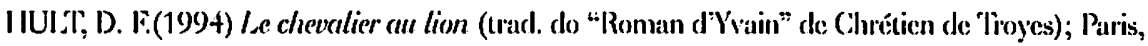
l.ettres gothicjues.

JACKSON, K. II. (trall.) (1971) A Cellic Miscellam); I ondon, Penguin.

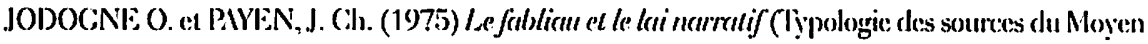
Age occidental, 1:3); I ouvain, Brepols Timoluent.

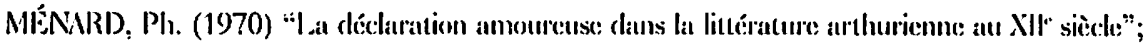
Cahiers de civilisation médiévale, n. 1, jan-mars, p. 3:3-42.

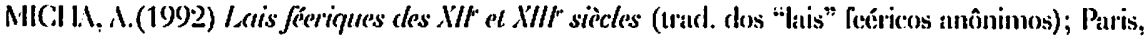
(FF Flammarion.

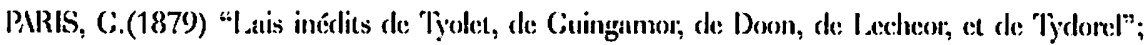
Romanir, 1.8, p. 29-72.

SJOESTEDT, M. -I. (1940) Dieux et héros des Celles; Paris, PUT.

VRIIES, J. de: (196:3) La religion des Celles; Paris, Payjol. 